\title{
Ultra-low noise supercontinuum source for ultra-high resolution optical coherence tomography at $1300 \mathrm{~nm}$
}

Bravo Gonzalo, Ivan; Maria, Michael; Engelsholm, Rasmus Dybbro; Feuchter, Thomas; Leick, L.; Moselund, P. M.; Podoleanu, Adrian; Bang, Ole

\section{Published in:}

Proceedings of SPIE

Link to article, DOI:

10.1117/12.2282412

Publication date:

2018

Document Version

Publisher's PDF, also known as Version of record

Link back to DTU Orbit

Citation (APA):

Bravo Gonzalo, I., Maria, M., Engelsholm, R. D., Feuchter, T., Leick, L., Moselund, P. M., Podoleanu, A., \& Bang, O. (2018). Ultra-low noise supercontinuum source for ultra-high resolution optical coherence tomography at $1300 \mathrm{~nm}$. In Proceedings of SPIE [104860N] SPIE - International Society for Optical Engineering.

Proceedings of SPIE - The International Society for Optical Engineering https://doi.org/10.1117/12.2282412

\section{General rights}

Copyright and moral rights for the publications made accessible in the public portal are retained by the authors and/or other copyright owners and it is a condition of accessing publications that users recognise and abide by the legal requirements associated with these rights.

- Users may download and print one copy of any publication from the public portal for the purpose of private study or research.

- You may not further distribute the material or use it for any profit-making activity or commercial gain

- You may freely distribute the URL identifying the publication in the public portal 


\section{Ultra-low noise supercontinuum source for ultra-high resolution optical coherence tomography at $1300 \mathrm{~nm}$}

I. B. Gonzalo, M. Maria, R. D. Engelsholm, T. Feuchter, L. Leick, et al.

I. B. Gonzalo, M. Maria, R. D. Engelsholm, T. Feuchter, L. Leick, P. M. Moselund, A. Podoleanu, O. Bang, "Ultra-low noise supercontinuum source for ultra-high resolution optical coherence tomography at $1300 \mathrm{~nm}$," Proc. SPIE 10486, Design and Quality for Biomedical Technologies XI, 104860N (19 February 2018); doi: 10.1117/12.2282412

SPIE. Event: SPIE BiOS, 2018, San Francisco, California, United States 


\title{
Ultra-low noise supercontinuum source for ultra-high resolution optical coherence tomography at $1300 \mathrm{~nm}$
}

\author{
I. B. Gonzalo*a, M. Maria, ${ }^{\mathrm{a}, \mathrm{b}, \mathrm{c}}$, R. D. Engelsholm ${ }^{\mathrm{a}}$, T. Feuchter ${ }^{\mathrm{c}}$, L. Leick ${ }^{\mathrm{c}}$, P. M. Moselund ${ }^{\mathrm{c}}$, A. \\ Podoleanu ${ }^{\mathrm{b}}$, and O. Bang ${ }^{\mathrm{a}, \mathrm{c}}$ \\ ${ }^{a}$ Department of Photonics Engineering, Technical University of Denmark, DK-2800 Kgs. Lyngby, \\ Denmark \\ ${ }^{\mathrm{b}}$ Applied Optics Group, School of Physical Sciences, University of Kent, Canterbury CT2 7NH, \\ United Kingdom \\ ${ }^{\mathrm{c}}$ NKT Photonics A/S, Blokken 84, DK-3460 Birkerød, Denmark \\ *ibag@fotonik.dtu.dk
}

Keywords: Optical Coherence Tomography, Supercontinuum, All-Normal Dispersion Fibers, Noise.

\section{ABSTRACT}

Supercontinuum (SC) sources are of great interest for many applications due to their ultra-broad optical bandwidth, good beam quality and high power spectral density [1]. In particular, the high average power over large bandwidths makes SC light sources excellent candidates for ultra-high resolution optical coherence tomography (UHR-OCT) [2-5]. However, conventional SC sources suffer from high pulse-to-pulse intensity fluctuations as a result of the noise-sensitive nonlinear effects involved in the SC generation process [6-9]. This intensity noise from the SC source can limit the performance of OCT, resulting in a reduced signal-to-noise ratio (SNR) [10-12]. Much work has been done to reduce the noise of the SC sources for instance with fiber tapers [7,8] or increasing the repetition rate of the pump laser for averaging in the spectrometer [10,12]. An alternative approach is to use all-normal dispersion (ANDi) fibers [13,14] to generate SC light from well-known coherent nonlinear processes [15-17]. In fact, reduction of SC noise using ANDi fibers compared to anomalous dispersion SC pumped by sub-picosecond pulses has been recently demonstrated [18], but a cladding mode was used to stabilize the ANDi SC.

In this work, we characterize the noise performance of a femtosecond pumped ANDi based SC and a commercial SC source in an UHR-OCT system at $1300 \mathrm{~nm}$. We show that the ANDi based SC presents exceptional noise properties compared to a commercial source. An improvement of $\sim 5 \mathrm{~dB}$ in SNR is measured in the UHR-OCT system, and the noise behavior resembles that of a superluminiscent diode. This preliminary study is a step forward towards development of an ultra-low noise SC source at $1300 \mathrm{~nm}$ for ultra-high resolution OCT.

\section{OPTICAL COHERENCE TOMOGRAHPY SETUP AND SUPERCONTINUUM SOURCES}

The ultra-high resolution optical coherence tomography (UHR-OCT) system used, shown in Fig. 1, is a Michaelson interferometer consisting of sample and reference arms. The broadband light from the supercontinuum (SC) laser source is split with a 50/50 directional coupler (DC) into both arms and the interference is recorded by a broadband (1070-1470 $\mathrm{nm}$ ) spectrometer (Wasatch Photonics - Cobra 1300). The spectrometer operates at maximum line-rate of $76 \mathrm{KHz}$ and with 2048 pixels. The sample arm consists of a reflective collimator (C1) to collimate the light from the fiber, a XY scanner and a scanning lens. The scanning lens produces a spot size of $11 \mu \mathrm{m}$. In the reference arm, the light is collimated by another reflective collimator (C2) and passed through a dispersion compensation block (Disp. C), and a neutral density filter to control the optical power. The data acquired and the processing is done using a home-designed LabVIEW interface and Matlab algorithm.

In this study, the noise performance of two different SC sources in an UHR-OCT system, as the one presented in Fig. 1, is investigated. Supercontinuum laser sources are excellent light sources for achieving ultra-high resolution, however, the noise of these sources is a limiting factor for OCT. The commercial SC sources are based on pumping a photonic crystal fiber (PCF) in the anomalous dispersion region, close to the zero-dispersion wavelength (ZDW), with high-power picosecond/nanosecond pulses. In this way, the SC is generated by modulation instability (MI) and soliton collisions, which are noise sensitive nonlinear processes [1,7-9]. By pumping with long pulses in the anomalous dispersion region, the SC is initiated by MI, resulting in noise amplification in the form of sidebands around the pump in the frequency

Design and Quality for Biomedical Technologies XI, edited by Ramesh Raghavachari, Rongguang Liang, Proc. of SPIE Vol. 10486, 104860N · C 2018 SPIE · CCC code: 1605-7422/18/\$18 · doi: 10.1117/12.2282412 
domain. In the time domain, MI breaks up the pulse into solitons. After this first stage, solitons collide and are shifted toward shorter frequencies due to Stimulated Raman Scattering (SRS), and dispersive waves generate the low frequency part of the SC spectrum [1]. Due to the nonlinear phenomena involved in the SC generation, commercial sources suffer from pulse-to-pulse intensity fluctuations leading to excess noise in the OCT or relative intensity noise (RIN). The RIN from the SC sources reduces the signal-to-noise ratio (SNR) of the OCT system [2, 10-12]. A solution to reduce the RIN in the OCT system is to increase the repetition rate of the SC laser to average over more pulses or in the same way, increase the exposure time of the spectrometer [10,12]. However, longer exposure times will lead to a slower acquisition, which can be a limitation if for instance, 3D images are required. An alternative approach to the commercial sources is to use all-normal dispersion (ANDi) fibers as the one shown in Fig. 2. By engineering the PCF (pitch and hole-to-hole distance), the dispersion can be normal over all the wavelengths of interest $[13,14]$. Consequently, MI and solitons are avoided because of the pumping in the normal dispersion region [1,15]. The SC generated by pumping an ANDi fiber with femtosecond pulses is initiated by self-phase modulation (SPM) and then followed by creation of new frequencies via optical wave breaking (OWB). Both processes are known to be coherent [15-18] and do not involve noise amplification.

We present here the SC sources used in the noise study: a commercial SC source (SuperK Extreme-NKT Photonics A/S operating at a repetition rate of $320 \mathrm{MHz}$ ) and femtosecond pumped ANDi based SC. The first source is a well-known commercial SC source, which has been used in other studies of noise in OCT [10-12]. The pump laser is a picosecond mode-locked laser with $\mathrm{kW}$ peak power and $1064 \mathrm{~nm}$ center wavelength, running at $320 \mathrm{MHz}$. This source belongs to the MI and solitons based type of SC explained above. The SC spectrum, measured with the spectrometer, is shown in Fig. 3a (red). The second SC source was built in our laboratory and has the following specifications: the pump laser is a femtosecond laser from Fianium (FemtoPower FP1060-fs) at $1064 \mathrm{~nm}$ with pulse width (full width at half maximum) of $\sim 165 \mathrm{fs}$, maximum average power of $5 \mathrm{~W}$ and $80 \mathrm{MHz}$ repetition rate. The femtosecond pulses from this laser are coupled into $\sim 0.4 \mathrm{~m}$ long commercially available ANDi fiber (NL-1050-NEG-1) and the resulting SC spectrum, measured with the spectrometer, is shown in Fig. 3a (blue). The noise properties of both SC sources are compared in the next section.

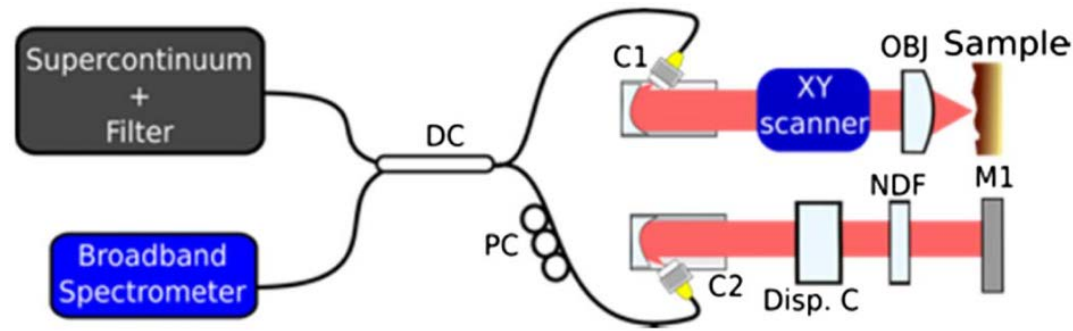

Figure 1. Sketch of the optical coherence tomography setup used in this study. DC-Directional coupler; PC-Polarization controller; C1 and C2-Reflective collimator; Disp. C-Dispersion compensation block; NDF-Neutral density filter; M1Mirror; OBJ-Scan lens.

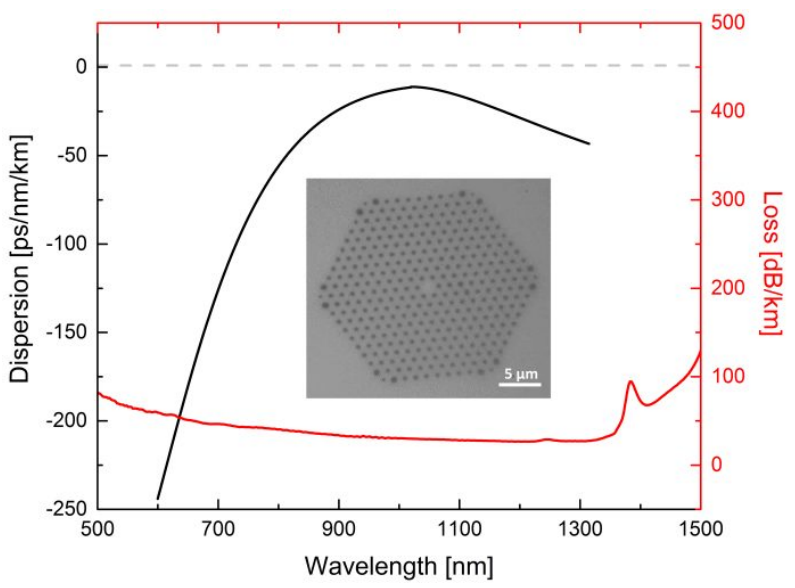

Figure 2. Measured dispersion profile (black) and loss (red) of the ANDi fiber (NL-1050-NEG-1) used to generate ANDi based SC with the femtosecond laser. The inset shows a microscope image of the cross section of the fiber. 


\section{NOISE COMPARISON}

Figure 3a shows the SC spectra of both sources measured with the spectrometer, by closing the sample arm of the UHROCT system (Fig. 1). The commercial SC source spans over the entire spectral range of the spectrometer (actually extends from 0.6 to $2 \mu \mathrm{m}$, but the SC was filtered), however the ANDi based SC only extends to $1370 \mathrm{~nm}$ in the long wavelength side. The extension of the ANDi SC was limited by the maximum average power coupled into the fiber before fiber damage. Furthermore, the ANDi SC spectrum shows some oscillations below $1120 \mathrm{~nm}$, not seen in the commercial source, which are attributed to SPM.
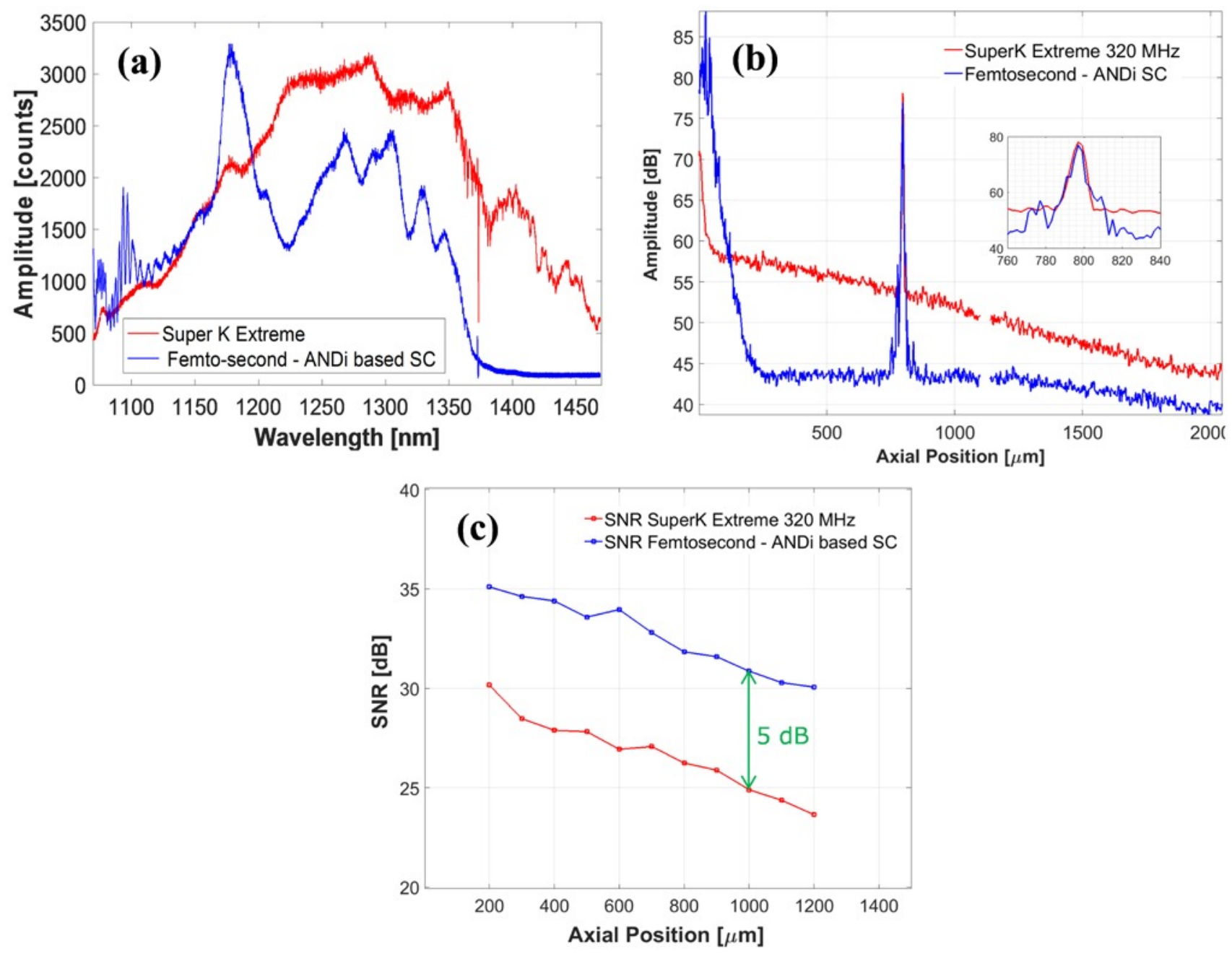

Figure 3. (a) SC spectra of SuperK Extreme $320 \mathrm{MHz}$ (red) and femtosecond ANDi based SC (blue) measured with the spectrometer. (b) A-scans at $800 \mu \mathrm{m}$ axial position for SuperK Extreme $320 \mathrm{MHz}$ (red) and femtosecond ANDi based SC (blue). The inset in (b) corresponds to the zoom in on the peak amplitudes. (c) Signal-to-noise ratio comparison calculated from A-scans at different axial positions [200-1200] $\mu \mathrm{m}$.

Noise measurements in the OCT systems are carried out for both sources using the following method: a perfectly reflecting sample (flat mirror) is placed in the sample arm and after post-processing of the interference signal, an A-scan, as the one given in Fig. $3 \mathrm{~b}$, is obtained. This is done for axial positions (moving the reference mirror mounted on a micrometer stage) in the range from $200 \mu \mathrm{m}$ to $1200 \mu \mathrm{m}$, and keeping approximately the same peak amplitude in the Ascan for both sources. The A-scans at $800 \mu \mathrm{m}$ axial position using the commercial source (red) and the ANDi based SC (blue) are shown in Fig. 3b. For the commercial SC source, the noise floor in the A-scan increases toward smaller axial positions, as shown before in other studies [10,12]. Contrary to the commercial SC source, the ANDi based SC shows a rather flat noise floor, which is below the noise floor of the commercial source except for axial positions smaller than 
$100 \mu \mathrm{m}$. For instance, the noise floor is more than $10 \mathrm{~dB}$ lower at $500 \mu \mathrm{m}$ axial position for the ANDi based SC. The noise floor curve resembles that of a superluminiscent diode [10]. This means that the noise of the ANDi based SC source is minimum and thus drastically reduced compared to the commercial source. Only for axial positions smaller than around $250 \mu \mathrm{m}$, the noise floor of the ANDi based SC starts to increase rapidly to get higher than the one of the commercial source at axial positions below $100 \mu \mathrm{m}$. In order to obtain the SNR, the maximum peak of the reflection (kept approximately at the same amplitude level for both sources) and the root mean square (RMS) of the noise floor are retrieved from the A-scans. The SNR, calculated as the ratio of the maximum peak to the RMS of the noise floor, shows around $5 \mathrm{~dB}$ improvement for the ANDi based SC compared to the commercial source. The SNR improvement is around $5 \mathrm{~dB}$ for all axial positions because the RMS of the noise floor is calculated for both sources at the deepest axial position.

Another factor to consider in the noise study is the repetition rate of the SC sources. For a fair comparison, the repetition rate of both sources should be the same since averaging of the pulses on the spectrometer has an impact on the noise floor of the A-scans, the more the average the lower the noise floor. However, no other sources were available at the moment of the experiment. In our case, the averaging (for the same exposure time, $20 \mu \mathrm{s}$, in the camera) is higher for the commercial SC source (320 MHz), whose repetition rate is 4 times higher than the ANDi based SC source (80 MHz). Consequently, the difference in SNR could be higher when comparing sources with the same repetition rate.

Figures 4 and 5 show measured B-scans of an IR card and the skin of a healthy volunteer, respectively. The optical power on the sample was around $2 \mathrm{~mW}$ for both sources. The images obtained with the ANDi based SC show a darker background than the images of the commercial source, as expected from the noise measurements above, and thus better contrast. However, images measured using the ANDi based SC source show a white signal in the upper part of the image due to the increase of the noise floor seen in the A-scans. This unwanted signal could be due to the SPM oscillations in the spectrum (Fig. 3a), which create interference at small axial positions and thus at the top of the B-scan.
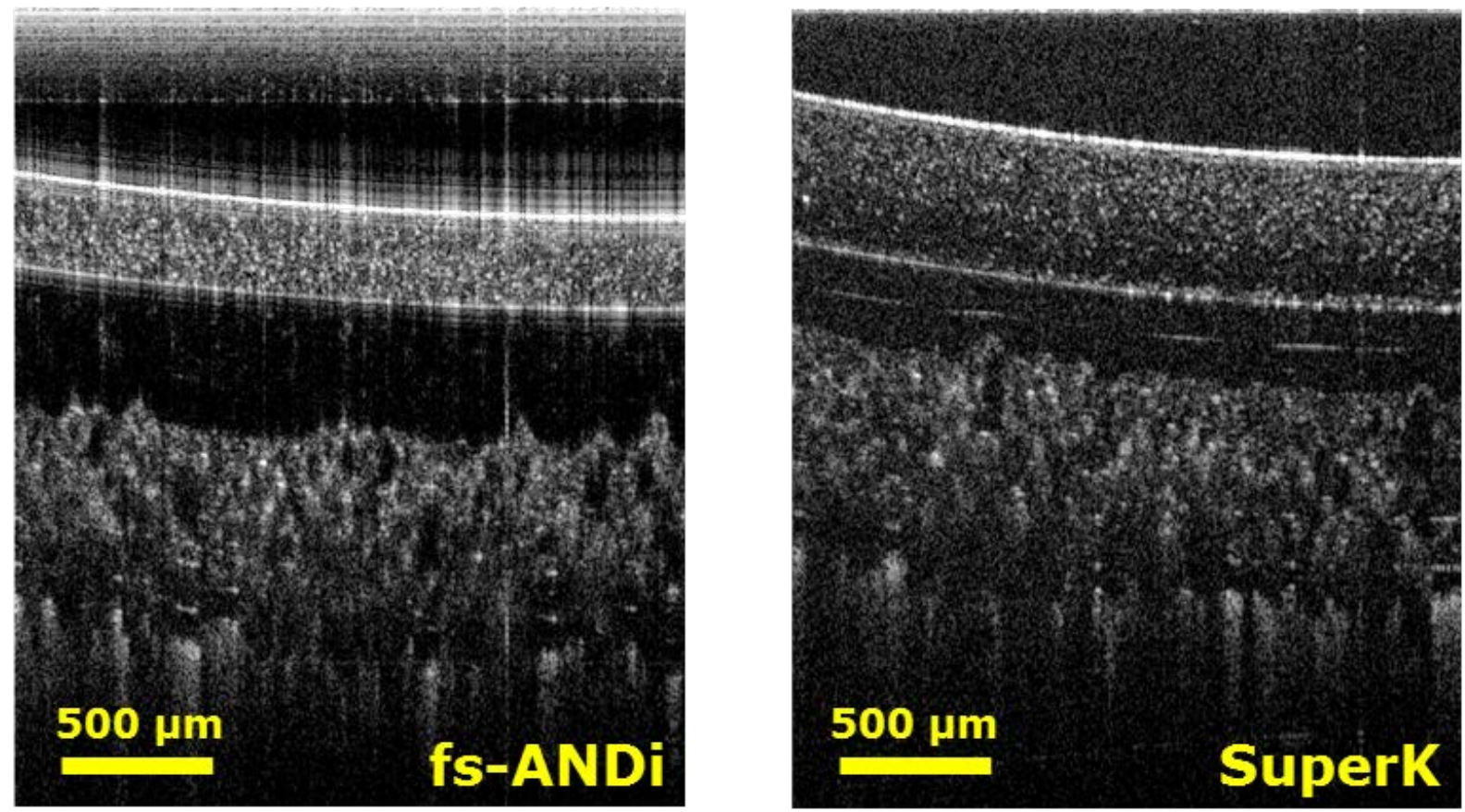

Figure 4. B-scans (1 mm x $2.4 \mathrm{~mm}$ ) of an IR card for fs-ANDi SC (left) and SuperK Extreme (right) using $2 \mathrm{~mW}$ optical power on the sample. To acquire the images, the exposure time is set to $20 \mu$ s corresponding to $40 \mathrm{KHz}$ line-rate of the camera. 

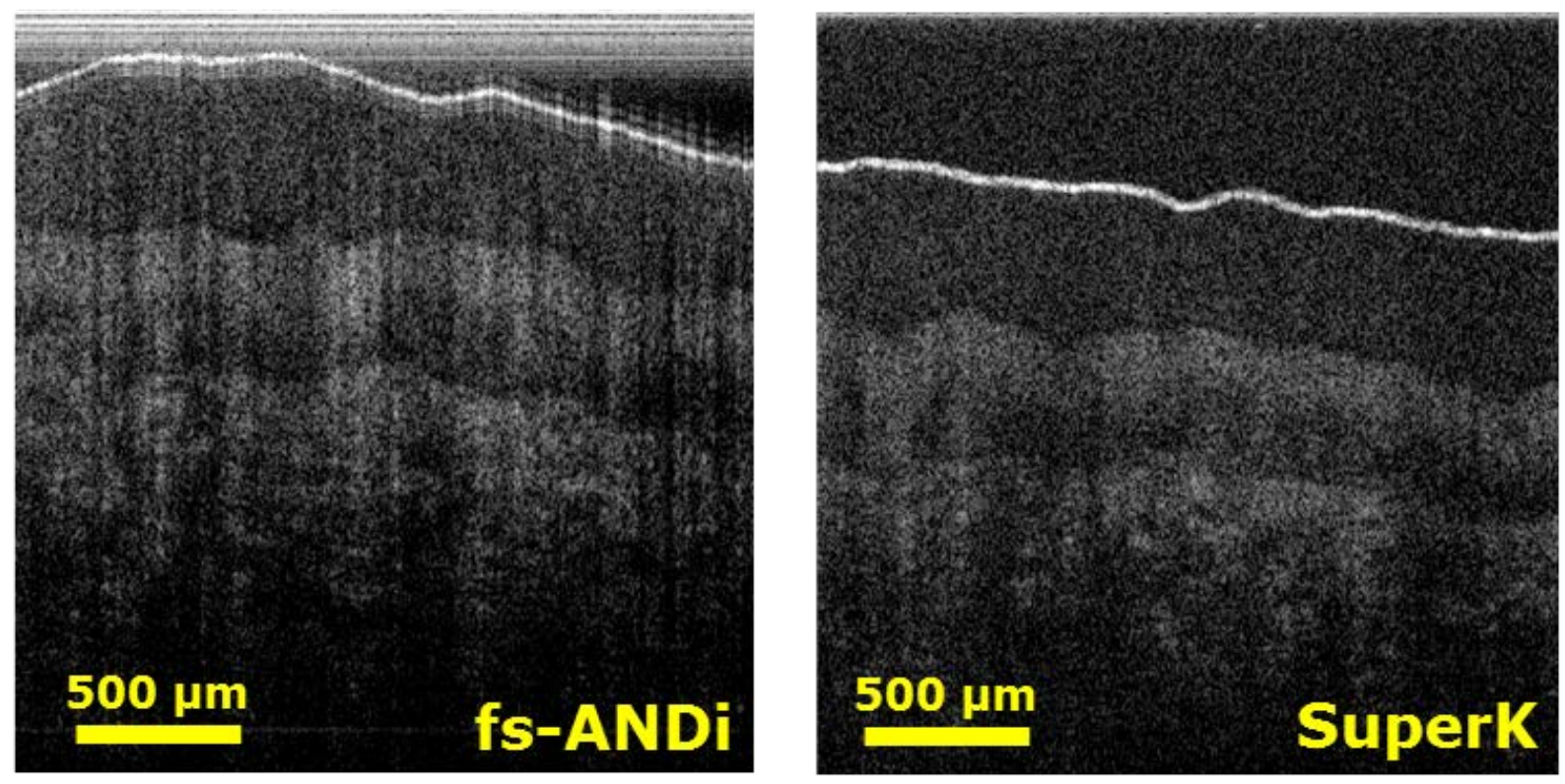

Figure 5. B-scans (1 mm x $2.4 \mathrm{~mm}$ ) of a healthy volunteer's palm skin for fs-ANDi SC (left) and SuperK Extreme (right) using $2 \mathrm{~mW}$ optical power on the sample. To acquire the images, the exposure time is set to $20 \mu$ s corresponding to $40 \mathrm{KHz}$ line-rate of the camera.

\section{CONCLUSIONS}

In conclusion, we have investigated the noise performance of two SC light sources in an UHR-OCT system at $1300 \mathrm{~nm}$. One of the SC sources is a commercial SC source recommended for OCT (SuperK Extreme $320 \mathrm{MHz}$ from NKT Photonics A/S), and the other SC source was built using a commercially available femtosecond laser source and a standard ANDi fiber. We demonstrate an improvement of around $5 \mathrm{~dB}$ in SNR by using the femtosecond pumped ANDi based SC over the commercial SC source. The ANDi based SC source exhibits not only broadband optical bandwidth suitable for UHR-OCT but also offers excellent noise properties comparable to that of superluminiscent diodes. Only at smaller axial positions than $100 \mu \mathrm{m}$ the noise of the ANDi based SC sources is higher than the one of the commercial source. The SNR improvement of ANDi based SC is also noticed in the images of IR card and skin, which have darker background and thus better contrast.

\section{ACKNOWLEDGMENTS}

The authors acknowledge support from Innovation Fund Denmark for the project ShapeOCT (J. No. 4107-00011A) and GALAHAD Horizon 2020 Framework Programme (H2020) (732613). IBG, OB and RDE acknowledge support from Det Frie Forskningsråd (DFF) (LOISE-4184-00532B), and MM and AP are also supported by the European Industrial Doctorate UBAPHODESA, FP7-PEOPLE2013-ITN 607627.

\section{REFERENCES}

1. J. M. Dudley, G. Genty, and S. Coen, "Supercontinuum generation in photonic crystal fiber," Rev. Mod. Phys. 78, 1135-1184 (2006).

2. W. Drexler and J. G. Fujimoto, Optical Coherence Tomography- Technology and Applications (Springer, 2015).

3. W. Drexler, "Ultrahigh-resolution optical coherence tomography," Journal of Biomedical Optics 9, (1 January 2004). http://dx.doi.org/10.1117/1.1629679

4. A. Baumgartner, C. K. Hitzenberger, H. Sattmann, W. Drexler, A. F. Fercher, "Signal and resolution enhancements in dual beam optical coherence tomography of the human eye," Journal of Biomedical Optics 3, (1 January 1998). http://dx.doi.org/10.1117/1.429861 
5. K. Bizheva, B. Tan, B. MacLelan, O. Kralj, M. Hajialamdari, D. Hileeto, and L. Sorbara, "Sub-micrometer axial resolution OCT for in-vivo imaging of the cellular structure of healthy and keratoconic human corneas," Biomed. Opt. Express 8, 800-812 (2017).

6. K. L. Corwin, N. R. Newbury, J. M. Dudley, S. Coen, S. A. Diddams, K. Weber, R. S. Windeler, "Fundamental noise limitations to supercontinuum generation in microstructure fiber," Phys. Rev. Lett. 90, 113904 (2003).

7. A. Kudlinski, B. Barviau, A. Leray, C. Spriet, L. Héliot, and A. Mussot, "Control of pulse-to-pulse fluctuations in visible supercontinuum," Opt. Express 18, 27445-27454 (2010).

8. U. Møller, S. T. Sørensen, C. Jakobsen, J. Johansen, P. M. Moselund, C. L. Thomsen, and O. Bang, "Power dependence of supercontinuum noise in uniform and tapered PCFs," Opt. Express 20, 2851-2857 (2012).

9. U. Møller and O. Bang, "Intensity noise in normal-pumped picosecond supercontinuum generation, where higher-order Raman lines cross into anomalous dispersion regime,” Electron. Lett. 49, 63-65 (2013).

10. W. J. Brown, S. Kim, and A. Wax, "Noise characterization of supercontinuum sources for low-coherence interferometry applications,” J. Opt. Soc. Am. A 31, 2703-2710 (2014).

11. Wu Yuan, Jessica Mavadia-Shukla, Jiefeng Xi, Wenxuan Liang, Xiaoyun Yu, Shaoyong Yu, and Xingde Li, "Optimal operational conditions for supercontinuum-based ultrahigh-resolution endoscopic OCT imaging," Opt. Lett. 41, 250-253 (2016).

12. M. Maria, I. B. Gonzalo, T. Feuchter, M. Denninger, P. M. Moselund, L. Leick, O. Bang, and A. Podoleanu, "Q-switch-pumped supercontinuum for ultra-high resolution optical coherence tomography," Opt. Lett. 42, 4744-4747 (2017).

13. J. P. Falk, M. H. Frosz, and O. Bang, "Supercontinuum generation in a photonic crystal fiber with two zerodispersion wavelengths tapered to normal dispersion at all wavelengths," Opt. Express 13, 7535-7540 (2005).

14. A. Hartung, A. M. Heidt, and H. Bartelt, "Design of all-normal dispersion microstructured optical fibers for pulse-preserving supercontinuum generation,” Opt. Express 19, 7742-7749 (2011).

15. A. M. Heidt, "Pulse preserving flat-top supercontinuum generation in all-normal dispersion photonic crystal fibers," J. Opt. Soc. Am. B 27, 550-559 (2010).

16. A. M. Heidt, J. S. Feehan, J. H. V. Price, and T. Feurer, "Limits of coherent supercontinuum generation in normal dispersion fibers,” J. Opt. Soc. Am. B 34, 764-775 (2017).

17. L. Liu, T. Cheng, K. Nagasaka, H. Tong, G. Qin, T. Suzuki, and Y. Ohishi, "Coherent mid-infrared supercontinuum generation in all-solid chalcogenide microstructured fibers with all-normal dispersion," Opt. Lett. 41, 392-395 (2016).

18. M. Klimczak, G. Soboń, R. Kasztelanic, K. M. Abramski, and R. Buczyński, "Direct comparison of shot-to-shot noise performance of all normal dispersion and anomalous dispersion supercontinuum pumped with subpicosecond pulse fiber-based laser,” Sci. Rep 6, 19284 (2016). 